\title{
The Error in the Special Theory of Relativity
}

IN his-rocent article, McCrea ${ }^{1}$ explains the apparent contradiction in the results obtained by Dingle ${ }^{2}$ from the special theory of relativity by pointing out that Einstein used two symbols to represent four different quantities. They are defined by Einstein quite carofully and distinguishod by qualifying phrases which do not, however, appear in the mathematical treatment. When I discussed this ambiguity some years ago $^{3,4}$, I suggested that if Einstein had used four separate symbols he would have avoided the mistake which he made later in his paper. This occurs in the round-trip "thought experiment" in which one of the essential qualifying phrases is omitted even in his descriptive account, thus leading to an incorrect rosult $t^{5,6}$. A brief reference is mado to this "experiment" in a comment in Nature" in which it is stated that the symmetry of the clocks is not preserved. Now this would be true in practice, but Einstein made no mention of any effects caused by acceleration nor did he make any allowance for them. If the "experiment" is carried out corroctly it should therefore give the same readings for the clocks as they would have when they are in uniform relative motion. The rosult given by Einstein does not follow from the "experiment" but from an assumption made implicitly that the clock which does the round trip is actually going slower than the one regarded as stationary and does not simply appear to go slower as viewed by the stationary obsorver.

This assumption may well be correct and is certainly reasonable. The important point to appreciate is that an additional assumption has been made. The confusion has arisen because of the belief held by Einstein and most writers on the subject that the result of the round-trip "experiment" follows from the initial postulates.

Einstein stressed the tentative nature of his theory and the need for experimental checks. Contrary to popular belief, there is no evidence concerning the special theory as propounded, because no experiment has been made in a force-free space. In practice, gravitational forces or accelerations are always involved 8 . There is now a certain amount of evidence that frequency shifts occur when atomic clocks are at different gravitational potentials or are subjected to rotational acceleration ${ }^{9,10}$.

\section{Essen}

50 Wensleydale Road,

Hampton, Middlesex.

Received November 19, 1967.

${ }^{2}$ McCrea, W. H., Nature, 216, 122 (1967).

${ }^{2}$ Dingle, H., Nature, 216, 119 (1967).

s Essen, L., Proc. Roy. Soc., A, 270,312 (1962).

"Essen, L., Nature, 180, 1061 (1957).

"Essen, L., in Air, Space and Instruments (edit. by Lees, S.) (McGraw-Hill, 1963).

'Essen, L., J. Inst. Elec. Eng., 9, 166, 389 (1963).

'Nature, 216, 113 (1967).

${ }^{8}$ Essen, L., Nature, 199, 684 (1963).

- Essen, L., Nature, 202, 787 (1964).

${ }^{10}$ Essen, J., Proc. Phys. Soc., 86, 671 (1965).

\section{The Case against the Special Theory of Relativity}

Prohessor McCrea's reply ${ }^{1}$ to my disproof of special relativity ${ }^{2}$ is both gratifying and disappointing. It is good that, at long last, soms comment has appeared; regrettable that this one contains nothing to tho point.

One simple thing only is needed to refuto the disproof, and it is essential-to show an error in the derivation of my equation (4) that does not invalidate equation (3). This I showed with unmistakable clearness. McCrea's only contribution to it is the following: "Dingle's (3) is meaningless. Correspondingly his (4) is meaningless." This, if true (it is not), would merely kill tho thoory in another way, for (3) is Einstein's deduction and that of all his followers until now.

Because this conclusively nullifies McCrea's rejoinder, $I$ should leave the matter here, with a final appeal to him now to agree frankly that the theory is untenable, but for the fact that tho overlooking of the irrelevant bulk of his statement would, in the prevailing state of thought, be misinterpreted. Nature's prediction" that "The chances are that most people will be persuaded by what [McCrea] has to say" would only too probably be verified. It is the general view that relativity is beyond the understanding of most, but must be accepted bocause somo mathematicians, who alone understand it, have endorsed it: criticism of it, being on this view merely a sign of incomprehension, can therefore be ignored if a sufficiently imposing mathematical dismissal, intelligible or not, is forthcoming. Euler faced the non-mathomatical sceptic, Diderot, with the challenge "Sir, $a+b^{n} / n=x$, hence God exists; reply!". Diderot did not reply and Euler's case prevailed. McCrea's statement has the same relevance and cogency as Euler's, and if met with silence would produce the same general conviction. Reluctantly, therefore, I dissect it.
First, all the didactic, as distinct from the polemical, part which oxpounds the mathematics of the theory is superfluous; I do not question it. I distinguished clearly between $(a)$ the mathematies and $(b)$ the identification of the mathematical symbols with observable quantities. I have enough mathematical insight to see that it is a waste of time to look for mathematical flaws in the theory. Hence McCrea's argument (i), which he says "alone is sufficient to refute Dinglc's contention", does not touch that contention. Of course, "equations (III) and (IV) [my (1) and (2)] concern two distinct sets of events, and so they cannot contradict each other". But what McCrea has to show, and has not shown, is why the physical result $(3)$, deduced from one set, can be held true, while the physical result (4), similarly deduced from the other (non-contradictory) set, must bo hold false.

Not only do I agree that my equations (1) and (2) are mathematically free from contradiction; I agree also that it is perfectly possible (though, of course, not necessary) that if the experiment were made the clocks described would give readings conforming to (1) and (2) (in which case, as far as can be seen at present, we should have to accept Lorentz's theory). But what is impossible is that, in that case, the settings of $H$ and $N$ in relation to $A$ and $B$, respectively, which, according to Einstcin's definition, synchronize the pairs, $A, H$ and $B, N$, would be such as to enable us to infer both his reading of $A$ for an event occurring on $H$ (thus yielding (3)) and a similarly determined reading of $B$ for an event occurring on $N$ (thus yiclding (4)). This I clearly stated.

McCrea's comments on this essential point of synchronization, which alone enables us to compare the readings of separated clocks, are revealing. If Einstein's comparison were, as he says, merely one of "two different ways 